\title{
Society and Mental Health
}

\section{Couple-Level Minority Stress and Mental Health among People in Same-Sex Relationships: Extending Minority Stress Theory}

\begin{tabular}{|c|l|}
\hline Journal: & Society and Mental Health \\
\hline Manuscript ID & SMH-19-0033.R2 \\
\hline Kanuscript Type: & Original Article \\
\hline Keywords: & $\begin{array}{l}\text { Stigma, Minority Stress, Same-Sex Couples, Mental health, Dyadic } \\
\text { Analysis }\end{array}$ \\
\hline Abstract: & $\begin{array}{l}\text { We simultaneously examined the effects of individual- and couple-level } \\
\text { minority stressors on mental health among people in same-sex } \\
\text { relationships. Individual-level minority stressors emerge from the } \\
\text { stigmatization of sexual minority individuals; couple-level minority } \\
\text { stressors emerge from the stigmatization of same-sex relationships. } \\
\text { Dyadic data from 100 same-sex couples from across the U.S. were } \\
\text { analyzed with Actor Partner Interdependence Models. Couple-level } \\
\text { stigma was uniquely associated with nonspecific psychological distress, } \\
\text { depressive symptomatology, and problematic drinking, net the effects of } \\
\text { individual-level stigma and relevant socio-demographic controls. } \\
\text { Analyses also show that couple-level minority stress played unique roles } \\
\text { in critical stress processes of minority stress proliferation: minority stress } \\
\text { expansion and minority stress contagion. The inclusion of couple-level } \\
\text { stress constructs represents a useful extension of minority stress theory, } \\
\text { enriching our capacity to deepen understandings of minority stress } \\
\text { experience and its application in the study of well-being and health } \\
\text { inequalities faced by vulnerable populations. }\end{array}$ \\
\hline
\end{tabular}

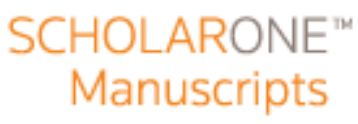


Couple-Level Minority Stress and Mental Health among People in Same-Sex

\section{Relationships: Extending Minority Stress Theory}




\begin{abstract}
We simultaneously examined the effects of individual- and couple-level minority stressors on mental health among people in same-sex relationships. Individual-level minority stressors emerge from the stigmatization of sexual minority individuals; couplelevel minority stressors emerge from the stigmatization of same-sex relationships. Dyadic data from 100 same-sex couples from across the U.S. were analyzed with Actor Partner Interdependence Models. Couple-level stigma was uniquely associated with nonspecific psychological distress, depressive symptomatology, and problematic drinking, net the effects of individual-level stigma and relevant socio-demographic controls. Analyses also show that couple-level minority stress played unique roles in critical stress processes of minority stress proliferation: minority stress expansion and minority stress contagion. The inclusion of couple-level stress constructs represents a useful extension of minority stress theory, enriching our capacity to deepen understandings of minority stress experience and its application in the study of well-being and health inequalities faced by vulnerable populations.
\end{abstract}

KEY WORDS: Same-Sex Couples, Mental Health, Minority Stress, Stress Process, Dyadic Analysis 


\section{BACKGROUND}

\section{Social Stress in Relational Contexts}

Distinguishing between individual- and couple-level sources of social stress allows for deeper understandings of stress experience, and how stress can be shared among individuals in the context of their intimate relationships (Frost, LeBlanc, de Vries, Alston-Stepnitz, Stephenson and Woodyatt 2017; LeBlanc, Frost, and Wight et al. 2015). Although stress frameworks have largely conceived of stress as emanating from individual experience, the reality that stress is typically shared with others has long been acknowledged, but not fully examined (Pearlin 1999; Pearlin and Bierman 2013). In this paper, we hope to deepen current understandings of how social stress and mental health can be usefully understood within relational contexts.

\section{The Proliferation of Role-Based Stressors}

Social stress is dynamic in people's lives; and it is often shared by individuals whose lives have become "linked" over time in enduring ways (Elder, Johnson, and Crosnoe 2003). Typically this has been observed in studies of people connected through traditional familial ties of blood or marriage (e.g., Bolger, DeLongis, Kessler, and Wethington 1989; Grzywacz, Almeida, and McDonald 2002; Young, Schieman, and Milkie 2014), although studies of AIDS caregiving have also focused on people connected by non-traditional familial ties (e.g., LeBlanc, London, and Aneshensel 1997; Pearlin, Aneshensel, and LeBlanc 1997; Wight, Aneshensel, LeBlanc, and Beals 2008). Following Merton's (1938) discussion of roles and role sets (e.g., spousal role or parental role vs. role sets such as linked spouses or parent and child), role-based framings have 


\section{illustrated how stress often expands (when stressors beget or exacerbate other stressors)} in an individual's life. They have also focused on how stress is often contagious (when

one person's stress causes stress for another). In a diverse body of research (cited above), such forms of stress proliferation, articulated in varying ways, have been shown to be associated with worse mental health.

\section{The Case of Minority Stress}

Minority stress frameworks have brought another useful lens to the study of social stress and mental health, and this lens has focused the importance of identities that are socially stigmatized. Just as social roles are a key frame for identifying the origins of stress, so is identity, as held by individuals; and, as we argue, jointly by individuals whose lives are linked as partners in a same-sex relationship.

In the classic presentation of minority stress theory, sexual minority individuals are viewed as potentially vulnerable to unique stressors, including: (1) experiences of discrimination (both acute events and chronic everyday mistreatment); (2) stigma or expectations of rejection; (3) concealment of a stigmatized identity; and (4) internalization of negative social beliefs about one's social groups or social identity (Meyer 2003). This conceptualization of minority stress stems from Goffman's classic works on stigma (1963) and impression management (1959). As such, minority stressors exist on a continuum of proximity to the self. Stressors most distal to the self are objective stressors based primarily in the environment, such as prevailing stereotypes, prejudice, and discrimination. These lead to more proximal appraisals of the environment as threatening, and to expectations of rejection (feeling stigmatized), as well as efforts to 
conceal or hide stigmatized identities (managing others' impressions). Most proximal to the self is one's internalization of negative social attitudes toward one's minority group (e.g., internalized homophobia).

\section{Moving from the Individual to the Couple Level}

Couple-level minority stressors may be experienced by individual partners, or jointly by couples, as a result of the stigmatized status of their relationship, in and of itself (LeBlanc et al. 2015). In other words, when their intimate relationships are devalued or diminished by society, individuals may face hardships or adversity as a result, which in turn diminish mental health. They may also face such challenges together - as couples - because their relationship represents a stigmatized relationship form. It is the source of this stress (i.e., society's marginalization of the relationship) that defines such stressors as couple-level minority stressors (LeBlanc et al. 2015), and this novel domain of minority stress is only beginning to be understood.

Although research on same-sex relationships has adopted a focus on minority stress (see review by Rostosky and Riggle 2018), it has only recently begun to more fully develop couple-level stress constructs. Researchers have investigated relationship marginalization (Lehmiller and Agnew 2006; 2007) and relationship stigma (Gamarel, Reisner, Laurenceau, Nemoto, and Operario, 2014; Rosenthal, Deosaran, Young, and Starks 2019; Rosenthal and Starks 2015), linking both to negative outcomes for individuals' relationship quality and well-being. Collectively, such studies have focused on same-sex, interracial, age-gap, and relationships where one partner is transgender, all relationship forms that are stigmatized by society, leading to unique stressors for the 
people in them.

A recent large-scale, in-depth qualitative study, has introduced a diverse range of novel, couple-level minority stress constructs, and these both parallel and diverge from the four primary individual-level minority stress constructs listed above (Frost et al. 2017). Moreover, a recent quantitative study presented compelling evidence that one such couple-level minority stressor - perceived unequal relationship recognition - is significantly associated with mental health outcomes, even after controlling for whether one's relationship is legally recognized (LeBlanc, Frost, and Bowen 2018).

Given that the disproportionate mental health burden faced by sexual minority populations (IOM 2011) is in part attributable to the mental health effects of minority stress (Hatzenbuehler, 2009; Hatzehbuehler, Phelan, and Link, 2013; Mays and Cochran, 2001; Meyer, 2003), there is great potential in broadening the minority stress universe to include a more refined focus on the relational context of stress. Ultimately, it may significantly contribute to the identification of previously unstudied stress processes involving stressors from multiple domains (e.g., generally experienced stressors, individual-level minority stressors, and couple-level minority stressors) that influence the mental health of each partner.

\section{Multiple Mental Health Outcomes}

Following the example of previous researchers who have focused on how pervasive social arrangements - such as those stemming from economic stratification and racism - influence mental health at the population level - we take a multiple-outcomes approach to the assessment of mental health (Aneshensel, 2005). This reflects a "social 
consequences" approach to the study of stress and mental health because the anticipated consequences of broad social factors, including those that stem from the stigmatization of sexual minority persons by society at large, are typically nonspecific. In other words, we expect that the effects of minority stress on mental health will not be limited to one particular disorder.

\section{The Current Study}

The current study uses a diverse dyadic sample of male and female same-sex couples to examine two primary research questions. These, alongside associated hypotheses, are as follows:

(1) Is couple-level minority stress negatively associated with mental health outcomes for people in same-sex relationships? Hypothesis 1a: Couple-level minority stress will be significantly associated with negative mental health outcomes among people in same-sex relationships. Hypothesis 1b: This association between couple-level minority stress and negative mental health outcomes will be independent of the association between individual-level minority stress and negative mental health outcomes among people in samesex relationships.

(2) Is couple-level minority stress part of dyadic minority stress processes of proliferation (i.e., expansion and contagion) that diminish the mental health of people in same-sex relationships? Hypothesis 2a: The experience of individual-level minority stress will be associated with greater couple-level minority stress (i.e., minority stress expansion from the individual-level to the 
couple-level). Hypothesis 2b: Minority stress will additionally be contagious between partners, whereby one person's experience of minority stress (at the individual-level and/or the couple-level) will be associated with their partner's experiences of minority stress and mental health.

These hypotheses are illustrated in Figure 1, which suggests some of the ways in which the addition of couple-level minority stress as a concept extends existing frameworks for the study of minority stress and mental health. To begin, individual partners may experience couple-level stress as a result of being part of a same-sex couple, and such stressors have the potential to negatively influence their own mental health (Pathways A-Actor, Hypothesis 1a). Moreover, we argue that such effects occur above and beyond the effects of individual-level minority stress experiences (Pathways A-Actor will remain significant above and beyond the effects illustrated with Pathways B-Actor,

\section{Hypothesis 1b).}

Additionally, this extended framework facilitates the examination of the extent to which couple-level minority stress experience plays a role in dyadic minority stress processes of proliferation (i.e., expansion and contagion). First, we examine whether the experience of individual-level minority stress among people in same-sex relationships can expand by increasing the likelihood they experience couple-level minority stress (Pathways C-Actor, Hypothesis 2a). Second, we consider the ways in which minority stress can be contagious between partners. These can be assessed through the identification of "partner" effects, which illustrate pathways linking each partner's stress experiences to those of their significant other. Pathways that illustrate these partner 
effects are labeled as follows: (1) Pathways C-Partner, linking one's individual-level minority stress experience to those of one's significant other; and (2) Pathways DPartner, linking one's couple-level minority stress experience to the mental health of one's significant other, Hypothesis $2 \mathbf{b}$ ). A third pathway that does not involve couplelevel minority stress, can also be examined in this framework (Pathways E-Partner, linking one's individual-level minority stress experience to the mental health of one's significant other), will also be considered.

\section{METHODS}

\section{Recruitment}

Data were from a dyadic study of 100 same-sex couples living in the U.S. Eligibility criteria for participation were: (1) both partners were age 21 or older; (2) both individuals must have perceived of themselves to be in a relationship with the other (i.e., forming a couple); and (3) they must have been engaged in a sexual relationship with one another at some point in their shared history. Couples including transgender individuals were not eligible to participate in recognition of the unique stressors that they face (Hendricks and Testa, 2012; Johnson, LeBlanc, Deardorff, and Bockting, 2019).

Study participants were recruited through a modified targeted nonprobability Internet-based recruitment strategy (Meyer, Schwartz, and Frost 2008; Meyer and Wilson 2009) implemented on a national scale. To begin, we identified a diverse array of online venue types from across the country, and then selectively filled "recruitment cells" to ensure sample diversity.

To create the online recruitment venue list, initial Google searches containing the 
terms "LGBT," "organization," and "name of state" were run in order to identify prominent LGBT online venues for each state. Each state had at least one LGBT center, and such centers were considered as online "hubs" for identifying additional online resources for sexual and gender minority populations. The websites for these centers typically offer a "resource" section where information about that state's LGBT-related organizations, groups, and activities is available, and such online resources were added to our venue list. Subsequent Google searches contained the terms "LGBT," "group," "event," "sports," "pride," "club," and "name of city and/or state," and these searches also pointed us toward additional online venues. Lastly, to locate venues more broadly focused, similar Google searches were conducted using the terms named above in combination with the terms, "national" and "regional."

Online recruitment venues were divided into the following two general types: (1) Online Communities, or those existing solely or primarily online, and (2) Organizations with an Online Presence, or organizations that have physical meeting spaces or sponsor social gatherings, but that also maintain a website or are active on social media (e.g., Facebook, Twitter). Next, they were then further categorized as follows, with two types of Online Communities ([1] Social/Leisure/Sports Groups and [2] Parenting Groups) and seven types of Organizations with an Online Presence ([1] LGBT Centers; [2] Arts Organizations; [3] Chambers of Commerce or Business/Professional Groups; [4] College- or University-based Organizations; [5] Political/Advocacy Organizations; [6] Planners and Organizers of Annual LGBT Pride Events; and [7] Religious Organizations/Associations. Ultimately, we identified over 1,500 online recruitment 
venues, each of which could be categorized as belonging to one of the nine venue types.

Through outreach to these venues, which included messaging through social media and e-mail communications - sometimes requiring the payment of advertising fees - persons interested in participating in the study were invited to complete a brief eligibility survey, which required only a few minutes of their time. Once both partners completed the eligibility survey, they were - if determined to be eligible - each individually invited to provide online consent and complete the full survey separately. If they did not meet eligibility criteria, they were not invited to continue. The full survey required about 45 minutes and each partner was electronically sent a \$30 Amazon gift card for completing it. The brief eligibility survey and the full survey were programmed and administered using Qualtrics. All study procedures were approved by the Institutional Review Board at the principal investigator's home institution. The first full survey was completed by a participant on July 21, 2015 and the final one was completed by a participant on January 21, 2016.

A number of efforts to minimize fraudulent participation were taken (Bauermeister, Pingel, Zimmerman, Couper, Carballo-Dieguez, and Strecher 2013). To begin, after completing the brief eligibility survey, all potentially eligible participants were then sent an e-mail invitation containing a unique survey link to complete the full survey. This full survey link could only be used by the recipient of this e-mail, which helped to ensure the validity of e-mail addresses given in the eligibility survey. Additionally, IP addresses for persons responding to the full survey were then compared with the zip code and state they provided in the eligibility survey to make sure they 
matched, and searches for the identification of IP addresses from which more than two surveys - one for each partner - originated were also conducted. Moreover, it was required that the eligibility survey be completed by each partner, and consequently their responses were compared to identify differences between partners in data describing their relationship. Finally, a small number of questions from the eligibility survey were repeated in the full survey, allowing for the identification of further data inconsistencies for individuals across the two surveys.

To ensure a diverse sample, we sought roughly equal distribution by couple gender and relationship duration (across three categories [ 6 months to $<3$ years; 3 years to $<7$ years; and 7 years or more]). As a result, we included "new" couples who have been together as few as six months in order to identify some of the early stressors that emerge through the process of relationship formation, some of which may have become too temporally distal for longer-term couples to remember in detail. A seven-year benchmark distinguishing long-term couples is in keeping with a general finding-from existing research on heterosexual marriages - that the risk of relationship dissolution increases in the early years, reaches a peak, and then steadily declines with time (Kulu 2014). We also sought to recruit participants equally from four regions of the U.S. (Midwest, Northeast, South, and West). Thus, we created 24 recruitment cells (3 relationship duration categories $\mathrm{X} 4$ regions, within each of the 2 sub-samples based on couple gender).

To further ensure sample diversity, we set quotas to ensure that at least $40 \%$ of participating couples were couples where at least one partner is a person of color, and that 
$20 \%$ reported residing in non-urban areas. Finally, to prevent an over reliance on particular venue types we required that at least two different venue types were referenced by the participants in each recruitment cell illustrated above.

\section{Sample}

In total, 1,804 individuals completed the brief eligibility survey. From this pool of respondents, 266 same-sex couples were identified as meeting eligibility criteria to participate. Initially, 106 couples completed the survey. Two couples did not provide valid data on the legal status of their relationship, and were excluded from further analyses. Four couples were not cohabiting and therefore were meaningfully distinct from the rest of the sample of cohabiting couples. They were also excluded from further analyses.

Thus, this paper focuses on 100 cohabiting couples, and the 200 individual partners who comprise those couples, who provided full data for the analysis at hand. As per the study design, the sample was nearly evenly distributed by couple gender $(46 \%$ Female, $54 \%$ Male), relationship duration ( $35 \% 6$ months to $<3$ years; $36 \% 3$ years to $<$ 7 years; and 29\% 7 years or more), and region of the country (29\% Midwest, $21 \%$ Northeast, 21\% South, and 29\% West). Forty-nine percent of participating couples were couples where at least one partner was a person of color. Twenty-four percent of couples resided in a rural area. Twenty-one percent were legally married - or both legally married and in a registered domestic partnership or civil union (RDP/CU) - while 19 percent were in a RDP/CU, but without being also legally married. Sixty percent were in relationships with no legal recognition. 
The individual partner-level data demonstrates that the mean age reported by sample respondents was 35 years. Fifteen percent identified as Spanish/Hispanic/Latino. In terms of race, about one fifth (17.5\%) of the sample identified as Black or African American; and smaller proportions identified as Asian (3\%) or Native Hawaiian or Pacific Islander (2.5\%). Just under three-quarters (72.5\%) of the sample identified as White $(67.9 \%)$. More than half had completed a bachelor's degree or additional education beyond that degree (56\%). Table 1 presents socio-demographic statistics that describe the sample.

\section{Minority Stress Measures}

Individual-Level Stigma. Individual-level stigma - a measure of individual-level minority stress - was measured with the six-item scale developed by Meyer and colleagues (2008). The scale, adapted from Link's (1987) work on stigma associated with mental illness, was applicable to multiple social categories at once. Respondents were presented with the following instructions: "These next statements refer to a person like you; by this we mean persons who have the same gender, race, sexual orientation, nationality, ethnicity, and/or socioeconomic class as you. In answering, we would like you to respond on the basis of how you feel people in general regard you in terms of such groups." Participants were then asked to indicate how much they agreed with the following statements: (1) Most employers will not hire a person like you; (2) Most people believe that a person like you cannot be trusted; (3) Most people think that a person like you is dangerous and unpredictable; (4) Most people think less of a person like you; (5) Most people look down on people like you; and (6) Most people think people like you are 
not as intelligent as the average person. Response categories were: (1) disagree strongly; (2) disagree somewhat; (3) agree somewhat; and (4) agree strongly. Responses to items in the measure were internally consistent (Cronbach's Alphas $=.89$ and .87 for Partners A and B, respectively). Summary scores were created by averaging each participant's responses across the six items. The mean score was $1.88(\mathrm{SD}=.18)$.

Couple-Level Stigma. Couple-level stigma - a measure of couple-level minority stress - was measured with the 10-item Couple-Level Stigma scale (Neilands, LeBlanc, Frost, Bowen, Sullivan, Hoff, and Chang 2019). Items elicited responses regarding the degree to which respondents' worried about the following: (1) If something happens to one of us the hospital won't recognize me or my [partner]; (2) Strangers will hassle us when we're eating in restaurants; (3) Showing affection for my [partner] when we are in new environments/unfamiliar places; (4) Strangers will harm us if we display affection in public; (5) Social situations may require me to explain more about my relationship than I want; (6) Our neighbors will discriminate against us; (7) That if something happens to my [partner], his/her family won't allow me to be included in the management of his/her affairs; (8) That if something happens to me, my family won't allow my [partner] to be included in the management of his/her affairs; (9) Retirement communities and nursing homes won't be accepting of us; and (10) My relationship with my [partner] would negatively affect my chances of getting or keeping a job. Response categories were: (0) not at all; (1) a little; (2) a moderate amount; (3) a lot; and (4) a great deal. Responses to items in the measure were internally consistent (Cronbach's Alphas $=.89$ and .87 for Partners A and B, respectively). This scale was created by averaging each participant's 
responses across the ten items. The mean score was $2.32(\mathrm{SD}=.18)$.

\section{Mental Health}

Reflecting a social consequences, multi-outcome approach, we include three mental health outcomes that were hypothesized to be similarly affected by the theorized minority stress processes. We have chosen one nonspecific mental health measure, the six-item K6 scale (Kessler, Andrews, Colpe, Hiripi, Mroczek, Normand, et al. 2002), and one disorder-specific measure, an abbreviated version of the Center for Epidemiologic Studies - Depression (CES-D) scale (Andresen, Malmgren, Carter, and Patrick 1994). The former is used to identity cases of serious mental illness from "non-cases," while the latter is focused specifically on assessing symptoms of depression in particular. The K6 scale was developed to screen for serious mental illness, including any DSM-IV disorder other than substance use disorder (Kessler, Barker, Colpe, Epstein, Gfroerer, Hiripi, et al. 2003). Thus, our inclusion of a measure that assessed problematic drinking - with items from the Alcohol Use Disorders Identification Test (AUDIT) (Saunders, Aasland, Barbor, de la Fuente, and Grant 1993) - added diversity to our list focal mental health outcomes. We consider these three mental health outcomes to represent distinct, though related, indicators for these analyses.

Nonspecific Psychological Distress. The K6 items elicited responses assessing how often respondents felt: (1) nervous; (2) hopeless; (3) restless or fidgety; (4) so depressed that nothing could cheer them up; (5) that everything was an effort; and (6) worthless, in the past 30 days. Response categories were: (0) none of the time; (1) a little of the time; (2) some of the time; (3) most of the time; and (4) all of the time. Responses 
to items in the measure were internally consistent (Cronbach's Alphas $=.93$ and .94 for Partners A and B, respectively). This scale was created by summing each participant's responses across the six items. The mean of the summed scores across the 200 individuals was $5.65(S D=6.20)$.

Depressive symptomatology. The CES-D included items assessing how often during the past week - respondents felt they were, for example: bothered by things that usually don't bother them; depressed; hopeful about the future, their sleep was restless; and lonely. Response categories were; (0) rarely or none of the time (less than 1 day); (1) some or a little of the time (1-2 days); (2) occasionally or a moderate amount of time (3-4 days); and (3) most or all of the time (5-7 days). Responses to items in the measure were internally consistent (Cronbach's Alphas were .79 and .74 for Partners A and B, respectively). This scale was created by summing each participant's responses across the ten items. The mean of the summed scores across the 200 individuals was $7.42(S D=$ 4.96).

Problematic Drinking. The AUDIT assessed both the frequency of drinking and related behaviors during the last year (e.g., failing to do what was normally expected because of drinking, having a feeling of guilt or remorse after drinking, and being unable to remember what happened the night before because of drinking). Higher scores were indicative of more problematic drinking (i.e., greater frequency and related behaviors). The AUDIT scale is typically comprised of 10 items. However, one item was unintentionally omitted from our survey, requiring us to rely on 9 items only. Consequently, the version we used in these analyses may have led us to underestimate the 
amount of problematic drinking as respondents had one fewer drinking-related item to select from. Responses to items in the measure were internally consistent (Cronbach's Alphas were .87 and .91 for Partners A and B, respectively). This scale was created by summing each participant's responses across nine items. The mean of the summed scores across the 200 individuals was $6.83(S D=6.46$.

\section{Control Variables}

Individual-Level Control Variables. Individual race/ethnicity, age, and education were assessed as follows, participants were asked to: (1) report whether they identify as Spanish, Hispanic, Latino, and which of the following best describe(s) their race or ethnicity (choosing all that apply): American Indian or Alaskan Native, Asian, Black or African-American, Native Hawaiian or Pacific Islander, White, or Something else not listed; (2) provide their date of birth; and (3) indicate the highest grade or year of school they had completed using the following response categories (no schooling completed, nursery or preschool through grade 12 [no diploma], high school diploma or equivalent, some college, associate's degree, bachelor's degree, master's degree, professional degree beyond a bachelor's degree, or doctorate degree).

Couple-Level Control Variables. All study participants responded to the following two questions (Sausa et al. 2009): (1) Which of the following best describe(s) your gender? (Response choices were man, woman, transmale/transman, transfemale/transwoman, genderqueer, or something else). (2) What sex were you assigned at birth? (What is the sex listed on your birth certificate)? Response choices were male or female. According to the eligibility criteria, all sample members were 
required to be cisgender male or cisgender female and to be a member of a same-sex couple, thus couple gender was treated as either male or female.

Each partner also responded to a survey question asking how long he/she had known his/her partner. If their responses differed, they were averaged. This measure of time known is analytically more useful than the three-category screener question used to determine whether couples met the eligibility criterion based on whether they had been together at least 6 months $<3$ years, 3 years $<7$ years, or 7 years or more, which was done to ensure diversity of relationship duration in the sample. Moreover, time known is especially relevant in the study of relationship forms that have historically lacked access to institutional and legal benchmarks of relationship recognition.

Relationship status was assessed with the following two survey questions: Are you and your (partner) currently legally married to one another? Are you and your (partner) currently living in a registered domestic partnership or civil union? This allowed us to distinguish between those legally married, those in an RDP or CU, those both legally married and in an RDP or CU, and those whose relationship was not legally recognized.

Finally, participants were asked to estimate their total household income before taxes during the past 12 months by checking one of 17 income categories, ranging from $\$ 0$ to $\$ 4,999$ to $\$ 1,000,000$ or more.

\section{Analytic Approach}

For the tests of the study's hypotheses, Actor Partner Interdependence Models (APIM; Kashy and Kenny 2000; Kenny 1996) were used to simultaneously examine 
associations between: (1) individual- and couple-level minority stressors - In this case focusing on the assessment of stigma (i.e., individual level stigma and couple-level stigma); and (2) both individual- and couple-level minority stressors and the three mental health outcomes. Three separate models were run for each outcome. Each of these models was run using structural equation modeling software in order impose equality constraints to account for the fact that same-sex couples are indistinguishable dyads (Kenny and Ledermann 2010). Additionally, in order to model the non-independence in the data that stems from the fact that all sampled individuals are nested within dyads, these models correlated the errors in the dependent variables and the predictor variables across partners (Olsen and Kenny 2006).

A number of control variables were included in these models. At the individuallevel we included: race/ethnicity ( 1 = person of color), age (years), and education. Education was collapsed into a dichotomous variable, distinguishing between those with (1) and without (0) the credential of a college degree (Ross and Mirowsky 1999). At the couple-level we included: gender $(1=$ women $)$; time known (years); legal marital status $(1=$ yes $)$; and household income. Household income was transformed and treated as continuous variable by assigning the midpoint of each income category.

\section{RESULTS}

\section{Couple-Level Minority Stress and Mental Health}

Table 2 presents APIM models where individual-level stigma and couple-level stigma are shown as determinants of each of the three mental health outcomes. All models included the control variables described above. These models explained between 
$28 \%$ and $45 \%$ of the observed variance in the three mental health outcomes under examination.

To begin, these models provide evidence to suggest that both individual- and couple-level stigma were significantly, independently, and positively associated with nonspecific psychological distress, depressive symptomatology, and problematic drinking. In other words, greater experiences of stigma - emerging from the stigmatization of one as a sexual minority individual and as a partner in a socially stigmatized relationship form - were associated with worse mental health. These models support the hypothesized associations (Figure 1, Hypothesis 1a and Hypothesis 1b) for actor effects of individual- and couple-level stigma on each partner's mental health (Pathways A-Actor and B-Actor in Figure 1).

\section{Dyadic Processes of Minority Stress Proliferation}

Further, these analyses suggest that couple-level minority stress experience plays a critical role in critical processes of minority stress proliferation. First, we see clear support for the hypothesis that minority stress expands from the individual- to the couplelevel. Statistics that portray minority stress expansion are not included in Table 2, because they are common to all three models. Specifically, the actor effect corresponding to the association between individual- and couple-level stigma was statistically significant, $\mathrm{b}=0.39, \mathrm{SE}=0.07, \mathrm{p}<.001, \beta=0.34$ (Figure 1, Pathways C-Actor, Hypothesis 2a). Similarly, the partner effect corresponding to the association between individual- and couple-level stigma was statistically significant, $\mathrm{b}=0.33, \mathrm{SE}=0.07, \mathrm{p}$ $<.001, \beta=0.29$ ) (Figure 1, Pathways C-Partner, Hypothesis 2a). 
Moreover, as presented in Table 2, these analyses suggest that minority stress contagion also occurs. First, we find evidence of partner effects in two of the APIM models - those predicting depressive symptomatology and problematic drinking, but not for the model predicting nonspecific psychological distress - wherein we found significant partner effects that suggest stress contagion between partners. In particular, we see significant effects where the one's partner's experience of a couple-level minority stressor (i.e., couple-level stigma) is associated with higher levels of one's own depressive symptomatology and problematic drinking (Figure 1, Pathways D-Partner,

\section{Hypothesis 2b).}

Indirect effects were tested using the bootstrapping procedures recommended by Shrout and Bolger (2002) and Preacher and Hayes (2008). Following these procedures, significant indirect effects are observed when the bootstrapped bias-corrected $95 \%$ confidence interval surrounding the estimate of the indirect effect does not include 0 . Evidence for individual and dyadic indirect effects were observed for all three mental health outcomes (Table 3). These analyses additionally illustrate how the stress proliferation processes of expansion and contagion are linked. Specifically, with regard to expansion within the individual level, the indirect effect of one's own experience of individual-level stigma on one's own mental health operated via increasing one's own experience of couple-level stigma. Similarly, we observed stress expansion that led to stress contagion. This was observed in the indirect effect of one's own experience of individual-level stigma on one's partner's mental health, which operated via increasing 
one's partner's experiences of couple-level stigma. Thus contagion of minority stress across partners was observed in this dyadic indirect effect.

Finally, we do not find evidence to suggest that individual-level minority stress contagion between partners in same-sex relationships is consequential for mental health (Figure 1, Pathways E-Partner). This rules out support, at least in this analysis, for this additional potential pathway of stress contagion.

Finally, there were significant associations between select control variables and the mental health outcomes under consideration (Table 2). Regarding individual-level controls: actor effects of race/ethnicity emerge in the models for nonspecific psychological distress and depressive symptomatology, and a partner effect was observed in the model for problematic drinking. We also observed a partner effect of education on nonspecific psychological distress and an actor effect on depressive symptomatology. At the couple level, women in same-sex relationships reported higher rates of psychological distress and depressive symptomatology than male couples.

\section{DISCUSSION}

This study based on dyadic data gathered from a diverse sample of 100 same-sex couples illustrates minority stress processes in new and important ways. As shown in Figure 1, the seemingly simple addition of a novel minority stress construct - couplelevel minority stress - has great potential for not only deepening current understandings of how minority stress affects mental health among men and women engaged in same-sex relationships, but also of persistent inequalities in mental health based on sexual orientation. This paper represents the first in-depth investigation of the role of couple- 
level minority stress in stress processes affecting the mental health of people facing social stigma, as individuals and as intimate partners.

Most fundamentally, these analyses provide support for the theory that couplelevel minority stressors significantly influence partner well-being; above and beyond the influence of individual-level minority stressors, which have been the focus of previous research (see Rostosky and Riggle (2017) for a review and Doyle and Molix (2015) for a meta-analysis). This study builds on emerging research into relational forms of stigma and its impact on health (e.g., Gamarel et al. 2014; Lehmiller and Agnew 2006; 2007; Rosenthal et al 2019; Rosenthal and Starks 2015) by conceptualizing, measuring, and analyzing the couple-level nature and dyadic context of stigma in relationships. In sum, our findings provide evidence that couple-level stigma is significantly and uniquely associated with a range of mental health outcomes, independently of the associations of individual-level stigma and both individual- and couple-level control variables with mental health.

They additionally highlight the utility of dyadic data, which allow for the identification of both actor- and partner-effects in the study of minority stress processes affecting mental health (i.e., the dyadic context of couple-level minority stress). In these dyadic analyses, we found both actor and partner effects of couple-level stigma on both depressive symptomatology and problematic drinking among people in same-sex relationships. Moreover, these analyses indicated that stress processes often involve stressors that emanate from multiple stress domains at the same time. In these analyses we simultaneously focused on minority stress as it is experienced by stigmatized 
individuals, as well as on minority stress as it is experienced by people engaged in a stigmatized relationship form. Findings illustrate the complexity of dyadic minority stress processes, as evident in our findings relating to minority stress expansion and proliferation. Future research with larger samples is needed to examine additional dyadic minority stress processes beyond those illustrated in Figure 1, including - for instance minority stress discrepancies between partners in same-sex couples (LeBlanc et al. 2015).

Relatedly, the current study also demonstrates the value of simultaneously examining stressors that are experienced in the context of social role obligations alongside those borne out of social stigma, at the individual and couple levels. Locating stress experience as it is tied to roles and/or identities - for example to the role of spouse or partner and the stigmatization of marginalized identities - may lead to important insights regarding the social structure of stress experience that could ultimately make it easier to predict and address. Continuing efforts to articulate new stress domains in the larger stress universe are an important step in that direction (Frost and LeBlanc, 2014; Thomeer et al. 2018; Wheaton 1999).

Finally, there are of course numerous additional relational contexts in which minority stress occurs among couples (e.g., inter-racial/ethnic, inter-faith couples), or within other types of dyads, such as within families in relationships between parents and children, and among siblings, and future theorizing and research should address those. Indeed, emerging research is beginning to address minority stress processes - and resilience to stress - within the familial context (Patterson 2002; Prendergast and MacPhee 2017; Smith and Landor 2018), and it appears that this work will be of great 
value as researchers continue to search for ways to embrace stress experience in its relational contexts.

\section{LIMITATIONS AND NEXT STEPS}

The present findings are based on a diverse, but relatively small and high SES, dyadic sample. This sample is also not representative of same-sex couples in the general population; such dyadic datasets do not exist. Our findings are also based on crosssectional data, and thus do not allow us to examine minority stress processes as they evolve over time. A sample of 100 same-sex couples limited the number of unique minority stressors - individual- or couple-level - that could be simultaneously examined in dyadic analyses. Larger samples are needed to more fully test the impact of a greater array of minority stressors that capture additional dimensions of minority stress experience (e.g., experiences of discrimination, identity concealment, and the internalization of stigma). For example, recent research has identified novel couple-level minority stress constructs (Frost et al. 2017; _ fruitfully analyzed as part of studies with larger samples, and samples with longitudinal data. In the present study we have focused on just one couple-level minority stress construct, couple-level stigma. Future studies with greater statistical power must also examine additional dimensions of well-being, with indicators of both physical and mental health beyond the three studied here. Additionally, future research can benefit from delving more deeply into additional forms of stress proliferation, which affect both relationship quality and partner well-being. 


\section{CONCLUSIONS}

The current study provides suggestive evidence of the previously theorized association between couple-level minority stress and mental health outcomes for people in same-sex relationships (LeBlanc et al. 2015). This evidence suggests that couple-level stigma represents a robust and consistent indicator of mental health problems for members of same-sex couples. Thus, couple-level stigma represents a previously underexamined risk to the mental health of sexual minority populations, above and beyond what sexual minority people experience as individuals. This study also provides evidence of important dyadic minority stress processes that potentially link individual experiences of minority stress to mental health through and within the relational domain. This study clearly indicates that couple-level minority stress should receive further attention within future research and intervention efforts focused on understanding and improving mental health among people in same-sex relationships or other stigmatized relationship forms. 


\section{REFERENCES}

Andresen, Elena M., Judith A. Malmgren, William B. Carter, and Donald L. Patrick. 1994. "Screening for Depression in Well Older Adults: Evaluation of a Short Form of the CES-D (Center for Epidemiologic Studies Depression Scale).” American Journal of Preventive Medicine 10:77-84.

Aneshensel, Carol S. 2005. "Research in Mental Health: Social Etiology versus Social Consequences.” Journal of Health and Social Behavior 46, 221-228.

Bauermeister Jose A., Emily Pingel, Marc Zimmerman, Mick Couper, Alex CarballoDiéguez, and Victor J. Strecher. 2013. "Data Quality in HIV/AIDS Web-Based Surveys: Handling Invalid and Suspicious Data.” Field Methods 24(3):272-91. Bolger, Niall, Anita DeLongis, Ronald C. Kessler, and Elaine Wethington. 1989. “The Contagion of Stress across Multiple Roles." Journal of Marriage and the Family $51,175-183$.

Doyle, D.M and L. Molix. 2015. “Social Stigma and Sexual Minorities’ Romantic Relationship Functioning: A Meta-Analytic Review.” Personality and Social Psychology Bulletin 41(10): 1363-1381.

Elder, Glen H., Jr., Monica Kirkpatrick Johnson, and Robert Crosnoe. 2003. “The Emergence and Development of Life Course Theory. Pp. 3-19 In Mortimer, J.T. \& M.J. Shanahan (Eds.), Handbook of the Life Course (pp. 3-19), New York, NY: Kluwer Academic/Plenum Publishers.

Frost, David M. and Allen J. LeBlanc. 2014. "Nonevent Stress Contributes to Mental Health Disparities Based on Sexual Orientation: Evidence from a Personal 
Projects Analysis.” American Journal of Orthopsychiatry, 84(5): 557.

Frost, David M. Allen J. LeBlanc, Brian de Vries, Eli Alston-Stepnitz, Rob Stephenson, and Cory Woodyatt. 2017. “Couple-Level Minority Stress: An Examination of Same-Sex Couples' Unique Experiences. Journal of Health and Social Behavior 58,455-472 https://doi.org/101177/0022146517736754.

Gamarel, Kristi E., Sari L. Reisner, Jean-Philippe Laurenceau, Tooru Nemoto, and Don Operario. 2014. “Gender Minority Stress, Mental Health, and Relationship Quality: A Dyadic Investigation of Transgender Women and Their Cisgender Male Partners. Journal of Family Psychology 28, 437-447.

Goffman, Erving. 1959. The Presentation of Self in Everyday Life, Doubleday: NY. Goffman, Erving. 1963. Stigma: Notes on the Management of a Spoiled Identity, Simon \& Schuster, Inc.: NY.

Grzywacz, Joseph G., David M. Almeida, and Daniel A. McDonald. 2002. "WorkFamily Spillover and Daily Reports of Work and Family Stress in the Adult Labor Force." Family Relations 51, 28-36. https://doi.org/10.1111/j.1741-3729.2002.00028.x

Hatzenbuehler, Mark L. 2009. "How Does Sexual Minority Stigma “Get Under the Skin”? A Psychological Mediation Framework. Psychological Bulletin 135(5), 707-730. http://dx.doi.org/10.1037/a0016441

Hatzenbuehler, Mark L., Jo C. Phelan, and Bruce G. Link. 2013. "Stigma as a Fundamental Cause of Population Health Inequalities.” American Journal of Public Health 103(5):813-821. 
Hendricks, Michael L. and Rylan J. Testa. 2015. “A Conceptual Framework for Clinical Work with Transgender and Gender Nonconforming Clients: An Adaptation of the Minority Stress Model." Professional Psychology: Research and Practice 43(5):460-467. doi:10.1037/a0029597

Institute of Medicine (IOM). 2011. The Health of Lesbian, Gay, Bisexual, and Transgender People: Building a Foundation for Better Understanding. Washington, DC: The National Academies Press.

Johnson, Kelly C., Allen J. LeBlanc, Julianna Deardorff, and Walter O. Bockting. 2019. "Invalidation Experiences among Non-binary Adolescents." The Journal of Sex Research http://doi.org/10.1080/00224499.2019.1608422.

Kashy, Deborah A. and David A. Kenny. 2000. "The Analysis of Data from Dyads and Groups." In H.T. Reis \& C.M. Judd (Eds.). Handbook of Research Methods in Social Psychology (pp. 451-78). New York: Cambridge University Press.

Kenny, David A. 1996. "Models of Nonindependence in Dyadic Research.” Journal of Social and Personal Relationships 13:279-294.

Kenny, David A. and Thomas Ledermann. 2010. "Detecting, Measuring, and Testing Dyadic Patterns in the Actor-Partner Interdependence Model. Journal of Family Psychology 24(3):359. DOI:10.1037/a0019651

Kessler R. C., G. Andrews, L. J. Colpe, E. Hiripi, D.K. Mroczek, S.-L. T. Normand, E. E. Walters, and A. M. Zaslavsky. 2002. "Short Screening Scales to Monitor Population Prevalences and Trends in Non-Specific Psychological Distress." Psychological Medicine 32:959-76. DOI: 10.1017/S0033291702006074 
Kessler R. C., P. R. Barker, L. J. Colpe, J. F. Epstein, J. C. Gfroerer, E. Hiripi, J.J. Howes, S-L T. Normand, R. W. Manderscheid, E. E. Walters, and A. M. Zaslavsky. 2003. "Screening for Serious Mental Illness in the General Population." Archives of General Psychiatry 60:184-189. doi:10.1001/archpsyc.60.2.184

King, Michael, Joanna Semlyen, Sharon See Tai, Helen Killaspy, David Osborn, Dmitri Popelyuk, and Irwin Nazareth. 2008. “A Systematic Review of Mental Disorder, Suicide, and Deliberate Self Harm in Lesbian, Gay and Bisexual People.” BMC Psychiatry 8:70. https://doi.org/10.1186/1471-244X-8-70

Kulu, Hill. 2014. "Marriage Duration and Divorce: The Seven-Year Itch or a Lifelong Itch?” Demography 51(3):881-93. doi: $\underline{\text { 10.1007/s13524-013-0278-1 }}$

Lehmiller, Justin J. and Christopher R. Agnew. 2006. "Marginalized Relationships: The Impact of Social Disapproval on Romantic Relationship Commitment.” Personal and Social Psychology Bulletin 32, 40-51. https://doi.org/10.1177/0146167205278710

Lehmiller, Justin J. and Christopher R. Agnew. 2007. "Perceived Marginalization and the Prediction of Romantic Relationship Stability." Journal of Marriage and Family 69, 1036-1049. https://doi.org/10.1111/j.1741-3737.2007.00429.x

LeBlanc, Allen J., David M. Frost, and Kayla Bowen. 2018. "Legal Marriage, Unequal Recognition, and Mental Health among Same-Sex Couples.” Journal of Marriage and Family 80, 397-408. https://doi.org/10.1111/jomf.12460

LeBlanc Allen J., Andrew S. London, and Carol S. Aneshensel. 1997. “The Physical 
Costs of AIDS Caregiving. Social Science and Medicine, 45, 915-923. https://doi.org/10.1016/S0277-9536(97)00002-6

LeBlanc Allen J., David M. Frost, and Richard G. Wight. 2015. "Minority Stress and Stress Proliferation among Same-Sex and Other Marginalized Couples.” Journal of Marriage and Family 77:40-59. https://doi.org/10.1111/jomf.12160

Link, Bruce G. 1987. "Understanding Labeling Effects in the Area of Mental Disorders: An Assessment of the Effects of Expectations of Rejection." American Sociological Review 52:96-112.

Mays, Vickie M. and Susan D. Cochran, S.D. 2001. "Mental Health Correlates of Perceived Discrimination among Lesbian, Gay, and Bisexual Adults in the United States." American Journal of Public Health 91:1869-76.

Meyer Ilan H. 2003. "Prejudice, Social Stress, and Mental Health in Lesbian, Gay, and Bisexual Populations: Conceptual Issues and Research Evidence." Psychological Bulletin 129, 674-97. doi: $\underline{10.1037 / 0033-2909.129 .5 .674}$

Meyer, Ilan H., Sharon Schwartz, and David M. Frost. 2008. "Social Patterning of Stress and Coping: Does Disadvantaged Social Statuses Confer More Stress and Fewer Coping Resources?” Social Science \& Medicine 67(3):368-79.

Meyer, Ilan H. and Patrick A. Wilson. 2009. "Sampling Lesbian, Gay, and Bisexual Populations." Journal of Counseling Psychology 56:23-31. DOI: $10.1037 / \mathrm{a} 0014587$

Olsen Joseph A. and David A. Kenny. 2006. "Structural Equation Modeling with Interchangeable Dyads." Psychological Methods 11(2):127. DOI: 


\section{$\underline{10.1037 / 1082-989 X .11 .2 .127}$}

Patterson, Joän M. 2002. "Integrating Family Resilience and Family Stress Theory." Journal of Marriage and Family 64:349-360.

Pearlin, Leonard I. 1999. “The Stress Process Revisited: Reflections on Concepts and Their Interrelationships. In Aneshensel, C.S., \& J.C. Phelan (Eds.), Handbook on the Sociology of Mental Health (pp. 395-415). New York: Kluwer Academic/Plenum Publishers.

Pearlin, Leonard I., Carol S. Aneshensel, and Allen J. LeBlanc. 1997. "The Forms and Mechanisms of Stress Proliferation: The Case of AIDS Caregivers." Journal of Health and Social Behavior 38, 223-236. DOI: 10.2307/2955368

Pearlin, Leonard. I. and Alex Bierman. 2013. "Current Issues and Future Directions in Research into the Stress Process." In Aneshensel, C.S. et al. (Eds.), Handbook of the Sociology of Mental Health, Second Edition, (pp. 325-340). New York: Springer Science+Business Media.

Preacher, K. J. and A. F. Hayes. 2008. “Asymptotic and Resampling Strategies for Assessing and Comparing Indirect Effects in Multiple Mediator Models." Behavior Research Methods 40:879-891.

Prendergast, Sarah and David MacPhee. 2017. "Family Resilience Amid Stigma and Discrimination: A Conceptual Model for Families Headed by Same-Sex Parents.” Family Relations 67(1):26-40. https://doi.org/10.1111/fare.12296

Shrout, Patrick E. and Niall Bolger. 2002. "Mediation in Experimental and Nonexperimental Studies: New Procedures and Recommendations.” 
Psychological Methods 7(4):422-445. DOI: 10.1037/1082-989X.7.4.422

Smith, Shardé McNeil and Antoinette M. Landor. 2018. "Toward a Better Understanding of African American Families: Development of the Sociocultural Family Stress Model." Journal of Family Theory \& Review 10:434-50. DOI: 10.1111?jftr.12260

Rosenthal, Lisa, Ashleigh Deosaran, DaSean L. Young, and Tyrel J. Starks. 2019.

"Relationship Stigma and Well-Being among Adults in Interracial and Same-Sex Relationships." Journal of Social and Personal Relationships OnlineFirst. DOI: $10.1177 / 0265407518822785$.

Rosenthal, Lisa and Tyrel J. Starks. 2015. "Relationship Stigma and Relationship Outcomes in Interracial and Same-Sex Relationships: Examination of Sources and Buffers.” Journal of Family Psychology 29(6):818-830. http://dx.doi.org/10.1037/fam0000116

Ross, Catherine E. and John Mirowsky. 1999. "Refining the Association between Education and Health: The Effects of Quantity, Credential, and Selectivity." Demography 36(4):445-460.

Rostosky, Sharon Scales and Ellen D.B. Riggle. 2017. "Same-Sex Relationships and Minority Stress.” Current Opinion in Psychology 13, 19-38. https://doi.org/10.1016/j.copsyc.2016.04.011

John B. Saunders, Olaf G. Aasland, Thomas F. Babor, Juan R. De La Fuente, and Marcust Grant. 1993. "Development of the Alcohol Use Disorders Identification Test (AUDIT): WHO Collaborative Project on Early Detection of Persons with Harmful Alcohol Consumption -- II.” Addiction 88:791-804. 
https://doi.org/10.1111/j.1360-0443.1993.tb02093.

Sausa LA, Sevelius J, Keatley J, Iñiguez JR, Reyes M. 2009. Policy recommendations for inclusive data collection of trans people in HIV prevention, care \& services. Center of Excellence for Transgender HIV Prevention: University of California, San Francisco. http://www. transhealth.ucsf.edu.

Thomeer, Mieke B., Allen J. LeBlanc, David M. Frost, and Kayla Bowen. 2018. “Anticipatory Minority Stressors among Same-Sex Couples: A Relationship Timeline Approach.” Social Psychology Quarterly, 81(2):126-148. https://doi.org/10.1177/0190272518769603

Wheaton, Blair. 1999. “Social Stress.” In Aneshensel, C.S. \& J.C. Phelan (Eds.), Handbook on the Sociology of Mental Health (pp. 277-300). New York: Kluwer Academic/Plenum Publishers.

Wight, Richard G., Carol S. Aneshensel, Allen J. LeBlanc, and Kristin P. Beals. 2008. Sharing an Uncertain Future: Improved Survival and Stress Proliferation among Persons Living with HIV and Their Caregivers. In Turner, H.A. \& S. Schieman (Eds.), Life Course Research: Stress Processes across the Life Course (pp. 369397). London: Elsevier (JAI).

Young, Marissa, Scott Schieman, and Melissa A. Milkie. 2014. "Spouse's Work-tofamily Conflict, Family Stressors, and Mental Health among Dual-earner Mothers and Fathers." Society and Mental Health, 4, 1-20. https://doi.org/10.1177/2156869313504931 


\section{Figgure 1. Extending Mlinority Stress Frameworks to Include Couple-Level Mlinority Stressors}

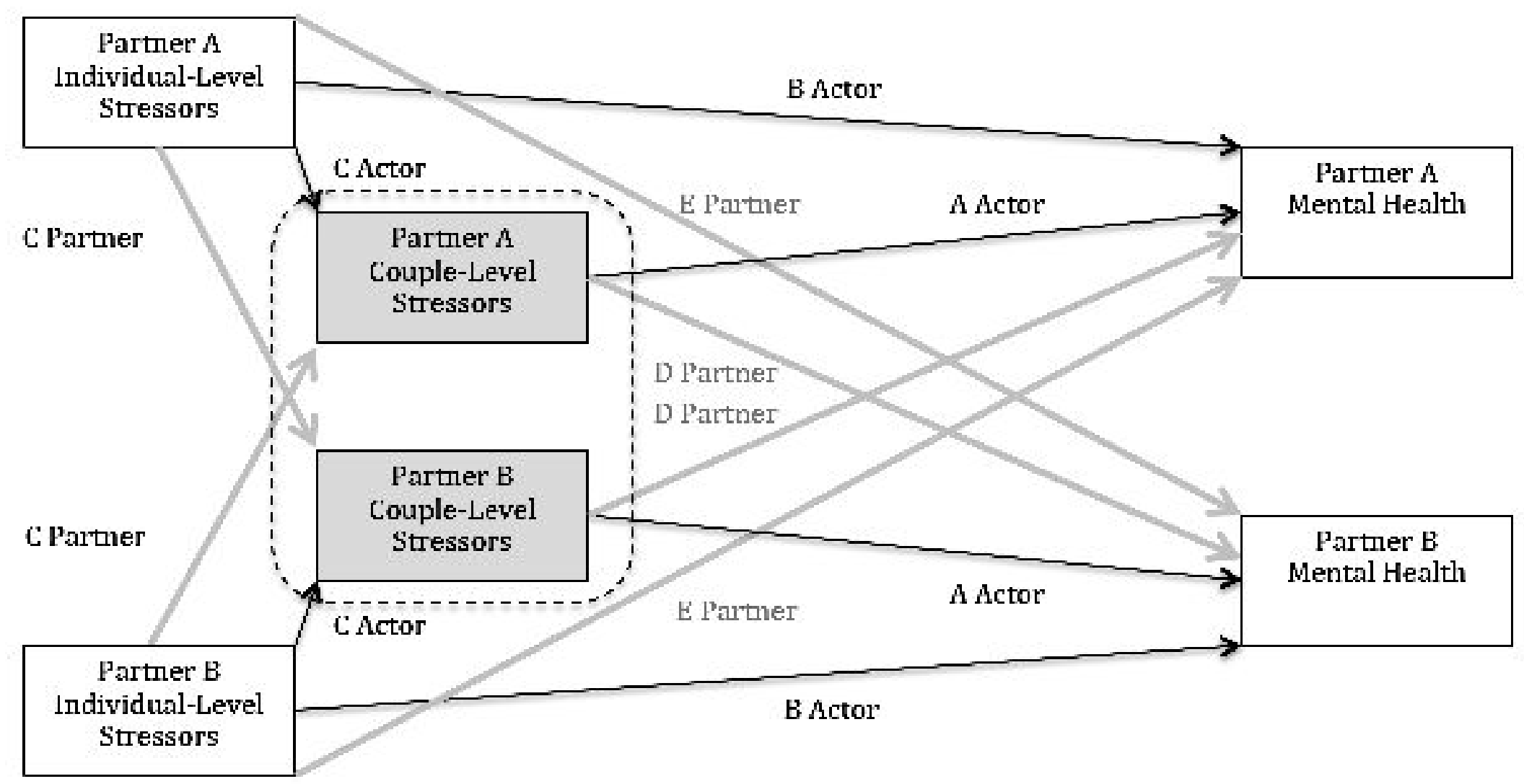


Table 1. Sample Descriptive Statistics for Individual and Couple Demographics

\begin{tabular}{|c|c|}
\hline COUPLE-LEVEL VARIABLES $(\mathrm{N}=100)$ & \\
\hline Gender $(1=$ Women $)$ & $n=46(46.0 \%)$ \\
\hline Race/Ethnicity ( $1=$ One/Both Partners is Person of Color) & $n=47(47.0 \%)$ \\
\hline \multicolumn{2}{|l|}{ Geographic Region of U.S. } \\
\hline Northeast & $n=21(21 \%)$ \\
\hline South & $n=21(21 \%)$ \\
\hline Midwest & $n=29(29 \%)$ \\
\hline West & $n=29(29 \%)$ \\
\hline Rural vs. Urban ( $1=$ Lives in a Rural Area $)$ & $n=24(24 \%)$ \\
\hline \multicolumn{2}{|l|}{ Relationship Status } \\
\hline Legally Married & $n=21(21 \%)$ \\
\hline Registered Domestic Partnership & $n=19(19 \%)$ \\
\hline Relationship Not Legally Recognized & $n=60(60 \%)$ \\
\hline Co-Parent Children $(1=$ Yes $)$ & $n=18(18 \%)$ \\
\hline \multicolumn{2}{|l|}{ Household Income ${ }^{\mathrm{a}}$} \\
\hline$\$ 0$ to $\$ 4,999$ & $n=1(1 \%)$ \\
\hline$\$ 5,000$ to $\$ 9,999$ & $n=1(1 \%)$ \\
\hline$\$ 15,000$ to $\$ 19,999$ & $n=2(2 \%)$ \\
\hline$\$ 20,000$ to $\$ 24,999$ & $n=2(2 \%)$ \\
\hline$\$ 25,000$ to $\$ 34,999$ & $n=2(2 \%)$ \\
\hline$\$ 35,000$ to $\$ 44,999$ & $n=3(3 \%)$ \\
\hline$\$ 45,000$ to $\$ 54,999$ & $n=3(3 \%)$ \\
\hline$\$ 55,000$ to $\$ 64,999$ & $n=4(4 \%)$ \\
\hline$\$ 65,000$ to $\$ 74,999$ & $n=15(15 \%)$ \\
\hline$\$ 75,000$ to $\$ 99,999$ & $n=31(31 \%)$ \\
\hline$\$ 100,000$ to $\$ 149,000$ & $n=29(29 \%)$ \\
\hline$\$ 150,000$ to $\$ 199,999$ & $n=5(5 \%)$ \\
\hline$\$ 200,000$ to $\$ 299,999$ & $n=1(1 \%)$ \\
\hline \multicolumn{2}{|l|}{ Relationship Duration } \\
\hline At least 6 months $<3$ years & $n=35(35 \%)$ \\
\hline 3 years $<7$ years & $n=36(36 \%)$ \\
\hline 7 years or more & $n=29(29 \%)$ \\
\hline Time Known (Years) & $M=7.83(S D=7.14)$ \\
\hline \multicolumn{2}{|l|}{ INDIVIDUAL-LEVEL VARIABLES $(\mathbf{N}=\mathbf{2 0 0})$} \\
\hline Ethnicity (1 = Spanish, Hispanic, Latino) & $n=30(15 \%)$ \\
\hline \multicolumn{2}{|l|}{ Race $^{b}$} \\
\hline American Indian/Alaskan Native & $n=7(3.5 \%)$ \\
\hline Asian & $n=6(3 \%)$ \\
\hline Black/African American & $n=35(17.5 \%)$ \\
\hline Native Hawaiian/Pacific Islander & $n=5(2.5 \%)$ \\
\hline White & $n=145(72.5 \%)$ \\
\hline Other & $n=4(2 \%)$ \\
\hline Education (Bachelor's Degree or Greater) & $n=112(56 \%)$ \\
\hline Age & $M=34.93(S D=8.7)$ \\
\hline
\end{tabular}

${ }^{\text {a }}$ In instances where two partners selected different household income categories, the couple was assigned a midpoint category if possible. If partners selected adjacent categories, the couple was assigned the higher of the two categories selected.

${ }^{\mathrm{b}}$ Participants may have self-identified with more than one race and therefore responses add up to more than $100 \%$. 
Table 2. APIM Models: Individual- and Couple-Level Minority Stress and Mental Health

\begin{tabular}{|c|c|c|c|c|c|c|c|c|c|}
\hline \multirow[t]{2}{*}{ Independent Variables } & \multicolumn{3}{|c|}{$\begin{array}{l}\text { Nonspecific Psychological Distress } \\
\text { (K6 } 0 \text { to 24) }\end{array}$} & \multicolumn{3}{|c|}{$\begin{array}{l}\text { Depressive Symptomatology } \\
\text { CES-D } 0 \text { to } 30\end{array}$} & \multicolumn{3}{|c|}{$\begin{array}{l}\text { Problematic Drinking } \\
\text { AUDIT } 0 \text { to } 36\end{array}$} \\
\hline & $b$ & $S E$ & $\boldsymbol{\beta}$ & $b$ & $S E$ & $\boldsymbol{\beta}$ & $\boldsymbol{b}$ & $S E$ & $\boldsymbol{\beta}$ \\
\hline \multicolumn{10}{|c|}{$\begin{array}{l}\text { Individual-Level Stigma } \\
\text { (Sexual Minority Stigma, 1-4) }\end{array}$} \\
\hline ACTOR EFFECT & $1.772 * *$ & .69 & .198 & $1.436^{* *}$ & .55 & .197 & $2.658 * * *$ & .57 & .289 \\
\hline PARTNER EFFECT & .916 & .69 & .102 & -1.019 & .55 & -.140 & 699 & .57 & .076 \\
\hline \multicolumn{10}{|c|}{$\begin{array}{l}\text { Couple-Level Stigma } \\
\text { (Expectations of Rejection, 1-4) }\end{array}$} \\
\hline ACTOR EFFECT & $1.312^{*}$ & .67 & .161 & $1.594 * *$ & .53 & .240 & $2.114 * * *$ & .54 & .253 \\
\hline $\begin{array}{c}\text { PARTNER EFFECT } \\
.14\end{array}$ & .735 & .67 & .090 & $1.072 *$ & .53 & .161 & $1.423 * *$ & .54 & .170 \\
\hline \multicolumn{10}{|l|}{ Individual-Level Controls } \\
\hline \multicolumn{10}{|c|}{ Race/Ethnicity $(1=$ Person of Color $)$} \\
\hline ACTOR EFFECT & $-2.091 *$ & 1.01 & -.167 & $1.568^{*}$ & .78 & .154 & .091 & .78 & .007 \\
\hline PARTNER EFFECT & .774 & 1.01 & -.062 & -1.777 & .78 & -.115 & $-1.472 *$ & .78 & -.115 . \\
\hline \multicolumn{10}{|l|}{ Age (Years) } \\
\hline ACTOR EFFECT & -.051 & .084 & -.071 & -.069 & .07 & -.119 & .054 & .07 & .074 \\
\hline PARTNER EFFECT & -.076 & .084 & -.108 & -.023 & .07 & -.041 & -.078 & .07 & -.108 \\
\hline \multicolumn{10}{|c|}{ Education ( 1 = Bachelor's or More $)$} \\
\hline ACTOR EFFECT & .324 & .75 & .026 & $1.206^{*}$ & .61 & .118 & -.490 & .65 & -.038 \\
\hline PARTNER EFFECT & $-1.613^{*}$ & .75 & -.129 & .483 & .61 & .047 & .051 & .65 & .004 \\
\hline \multicolumn{10}{|l|}{ Couple-Level Controls } \\
\hline Time Known (years) & -.075 & .11 & .088 & 144 & .09 & .206 & -.002 & .11 & -.003 \\
\hline Legally Married (1 = yes) & 984 & .98 & -.065 & -.590 & .87 & -.048 & .000 & 1.02 & -.003 \\
\hline Household Income & .000 & .00 & -.021 & -.021 & .00 & -.068 & -.298 & .00 & .016 \\
\hline Gender $(1=$ women $)$ & $1.279^{*}$ & .80 & .139 & $1.941^{* *}$ & .71 & .192 & .046 & .83 & -.034 \\
\hline $\mathbf{R}^{2}$ & .306 & & & .448 & & & .275 & & \\
\hline
\end{tabular}

Note. AUDIT $=$ Alcohol Use Disorders Identification Test; CES-D = Center for Epidemiologic Studies Depression Scale.

${ }^{*} p \leq .05 .{ }^{* *} p \leq .01 .{ }^{* * *} p \leq .001$. 
Table 3. Test of Indirect Effects of Individual-Level Stigma on Mental Health Outcomes via Couple-Level Stigma.

\begin{tabular}{lccc}
\hline \hline & & \multicolumn{2}{c}{$95 \%$ BC CI } \\
Indirect Effects & $\mathrm{b}$ & Lower & Upper \\
\hline Stigma Individual --> Stigma Couple-Level --> K6 (Actor) & 0.68 & 0.02 & 1.29 \\
Stigma Individual --> Stigma Couple-Level --> K6 (Partner) & 0.64 & 0.004 & 1.26 \\
Stigma Individual --> Stigma Couple-Level --> CESD (Actor) & 0.99 & 0.44 & 1.64 \\
Stigma Individual --> Stigma Couple-Level --> CESD (Partner) & 0.95 & 0.44 & 1.55 \\
Stigma Individual --> Stigma Couple-Level --> AUDIT (Actor) & 1.28 & 0.54 & 2.11 \\
Stigma Individual --> Stigma Couple-Level --> AUDIT (Partner) & 1.22 & 0.46 & 2.11 \\
\hline \hline
\end{tabular}

Note: Indirect effects and corresponding bias corrected $95 \%$ confidence intervals (BC CI) were calculated using bootstrap sampling with 1,000 samples. Indirect effects are considered statistically significant at the .05 level if their corresponding CIs do not contain 0 . 